\title{
A demanda por empreender: uma proposta para o estudo do empreendedorismo de acordo com a psicologia social do trabalho
}

\author{
Flávia Manuela Uchôa de Oliveira ${ }^{1}$ \\ Universidade de São Paulo (São Paulo, SP, Brasil)
}

Este artigo busca estabelecer uma proposta para o estudo do empreendedorismo a partir da perspectiva da psicologia social do trabalho. Tal proposta surge da necessidade de repensar o anúncio constante de que "somos todos empreendedores", assim como da necessidade de pensar as várias formas de trabalho para além do emprego e do trabalho regulamentado nomeadamente, a polimorfia do trabalho -, e como estas foram governamentalizadas a partir do final do século XX. Para este exercício, utilizamos a noção desenvolvida em pesquisa anterior, sobre o empreendedorismo pensado como uma demanda. Argumentamos que tal demanda funciona como um dispositivo de governo neoliberal e que estabelece uma continuidade colonial, impondo uma determinada modernidade a ser alcançada. Concluímos indicando que a demanda empreendedora torna a "viração" uma forma de governar o trabalho e os trabalhadores.

Palavras-chave: Empreendedorismo, Polimorfia do trabalho, Governamentalidade, Psicologia social do trabalho.

Entrepreneurial demand: a research agenda for entrepreneurship within the Social Psychology of Work

This paper presents a research agenda for entrepreneurship within Social Psychology of Work. This agenda emerges from the need to rethink the recurrent announcement that "we are all entrepreneurs". Likewise, it arises from the need to think about the various forms of work - namely, the polymorphism of work - and how these forms have been governmentalized since the end of the last century. We suggest a different approach to entrepreneurship, understanding it as a demand. We argue that this demand functions as a neoliberal device and establishes a colonial continuity, imposing a certain modernity that societies must achieve. We conclude by presenting how this entrepreneurial demand governmentalizes non-regulated forms of work.

Keywords: Entrepreneurship, Polymorphism of work, Governmentality, Social psychology of work.

\section{Introdução}

E ste artigo busca estabelecer uma proposta para o estudo do empreendedorismo a partir da perspectiva da psicologia social do trabalho (PST), o que quer dizer que partimos de um solo específico para uma compreensão renovada do empreendedorismo.

A psicologia social do trabalho de que falamos é aquela que surge a partir da década de 1980, no final do período de ditadura militar-empresarial no Brasil. Essa perspectiva tem suas raízes na leitura da psicologia social e da saúde do trabalhador. Surge e vai em compasso com as ciências sociais, valendo-se de uma leitura multi e transdisciplinar. Utiliza contribuições da filosofia, da sociologia, da antropologia e da geografia humana para constituir-se entre fronteiras (Sato, 2003). Seu compromisso ético e político é estabelecido com as trabalhadoras e trabalhadores, sendo gestado historicamente no movimento sindical.

Para Bastos (2019, p. 14), essa perspectiva pode "ser caracterizada como uma espécie de Psicologia do Trabalhador", e o seu corpus de estudo é obtido em outros espaços que não somente as empresas e as instituições, efetivando uma resistência à hegemonia da visão do objeto trabalho em sua versão "formal" e "protegida". Na PST, o trabalho é categoria central de análise, o que

1 https://orcid.org/0000-0002-6847-8436 
impossibilita separar as condições concretas de trabalho daquilo que se efetiva na rotina dos trabalhadores (Sato, Coutinho \& Bernardo, 2017, p. 13).

Dos trabalhos nessa perspectiva, são pioneiros os estudos de Leny Sato (1993, 2002, 2003, 2009, 2011, 2012, 2017). Sato (2017, pp. 163-170) estabeleceu as bases para uma noção de trabalho como um caleidoscópio, o que quer dizer que o trabalho tem várias e diferentes formas que se conectam, produzindo novas formas: essa é a noção de "polimorfia do trabalho" pensada pela autora. Para ela, essa polimorfia pode ser identificada pelos seguintes aspectos: o trânsito dos trabalhadores urbanos entre as áreas centrais e periféricas do trabalho, as redes de ajuda mútua e de criação do trabalho, os laços familiares como unidade de criação de sustento; a criação ou combinação das materialidades e experiências para criar trabalho; e, ainda, a criação de trabalho que faça sentido para o lugar em que se está, ou seja, o que o lugar, seus costumes e rotinas informam e requisitam do trabalhador.

A compreensão da polimorfia do trabalho busca superar o pensamento dicotômico entre formal e informal, colocando-os em relação, tratando das múltiplas inserções paralelas e interpostas na formalidade e na informalidade, na legalidade e na ilegalidade ${ }^{2}$. A nosso ver, o que Sato (2017) intenciona ao formular essa noção é mostrar que trabalho não se iguala a emprego, isto é, que o trabalho não é equivalente a uma forma "pura" e permanente; que o emprego está posto em uma rede mais ampla, para além da formalidade; e que, enfim, o trabalho é mais que a inserção econômica - é, primordialmente, uma inserção no social.

Utilizamos a noção de polimorfia, por exemplo, para pensar o trabalho de campo de nossa pesquisa de doutorado (Uchôa de Oliveira, 2020). Conversamos com mulheres que eram a um só tempo diaristas e auxiliares de limpeza terceirizadas e que já haviam sido empregadas domésticas "registradas"; com um aposentado que trabalha como marceneiro e tem uma loja de artigos variados (de material de papelaria a roupas); com um promotor de vendas de uma indústria de bebidas que também é traficante; com um traficante que faz "bicos" como pintor, é ajudante de obras e estava "colocando currículo" em busca da "carteira assinada"; com uma diarista que também é cuidadora de idosos e que transforma sua casa de novembro a fevereiro em ateliê de costura e montagem das fantasias de uma escola de samba. É nesse sentido que o trabalho é polimórfico.

Ademais, partindo dessa noção, em nossa tese, buscamos analisar o empreendedorismo. Entendemos empreendedorismo de maneira ampla, como a principal forma de inserção individual no mercado de trabalho.

$\mathrm{Na}$ análise empreendida na tese de doutorado (Uchôa de Oliveira, 2020), partimos de duas caracterizações. A primeira, do empreendedorismo como um instrumento para governamentalizar ${ }^{3}$ as várias formas de trabalhar. O que chamamos de governamentalização da polimorfia do trabalho, ou seja, tornar instrumento de governo as várias formas de trabalhar que, muitas vezes, são reunidas sob o título de empreendedorismo: a viração, o bico, as "ôias" e o freelance.

A segunda, do empreendedorismo não pelo ou localizado no empreendedor (em seu comportamento, espírito e motivação), mas por aquilo que do empreendedor é demandado, e como tal demanda é produzida e circula em nosso país.

Foi a partir do estudo da polimorfia do trabalho que identificamos o empreendedorismo como uma demanda específica, instrumento de regulação e condução do trabalho, dos trabalhadores e, ao fim e ao cabo, da vida em sociedade.

Portanto, neste artigo, nossa base é a caracterização do tema conforme apresentada em nossa tese de doutorado. E, com o intuito de apresentá-la em mais detalhes, estabelecemos aqui a seguinte sequência: mostramos elementos empíricos para ampliar nossa compreensão do empreendedorismo,

2 Para uma perspectiva sobre os termos formal e informal, ver Spink (2012). Os localizadores estabelecidos pelo autor, no prefácio do livro Feira livre: organização, trabalho e sociabilidade, de Leny Sato (2012), problematizam os "espaços de movimentação" dos trabalhadores no Brasil. Termos como formal e informal são repensados, o que nos fornece outros olhares para lidar com esse binômio.

3 Referimo-nos aqui à ideia de governamentalidade como pensada por Michel Foucault e explorada mais à frente.

\section{6}


especialmente em nosso país. Logo depois, indicamos os instrumentos de pensamento com os quais propomos análises acerca do tema. Por fim, desenvolvemos nossa proposta de estudo do empreendedorismo.

\section{"Somos todos empreendedores"}

Empreendedorismo e empreendedor são palavras-chave utilizadas para explicar, caracterizar e analisar os indivíduos e, ao mesmo tempo, nossa sociedade. Da mesma forma, o anúncio de que "somos todos empreendedores" está posto em muitos e diversos lugares. Ao observarmos o contexto brasileiro, por exemplo, esse anúncio está literalmente exposto na capa da edição 345 da revista Pequenas Empresas $\mathscr{G}$ Grandes Negócios (PEGN), publicada em outubro de 2017. Menos literais, outras chamadas nessa mesma revista incitam em suas capas: "seja seu próprio patrão", "dê adeus ao chefe" e "faça a sua história". São anúncios produzidos e sustentados por uma rede intrincada de especialistas, instituições, organizações, em que a exigência vem sempre acompanhada por uma forma de aprendizado: "Saiba como fazer", "aprenda", "desenvolva", "pratique", em suma, "aprenda a empreender".

Essa incitação a aprender a empreender ganhou força a partir dos anos 1990 em nosso país (Fernandes, 2019; Uchôa de Oliveira, 2020). Em 1988, o programa de TV Pequenas Empresas $\mathcal{E}$ Grandes Negócios foi exibido pela primeira vez, sucedido pelo lançamento da revista de mesmo nome em 1989. Ambos, programa de TV e revista, foram elaborados e patrocinados pelo Serviço Brasileiro de Apoio às Micro e Pequenas Empresas (Sebrae). O Sebrae é hoje o "principal parceiro" dos empreendedores no Brasil, voltado apenas aos pequenos negócios, conforme a descrição do próprio serviço (Serviço Brasileiro de Apoio às Micro e Pequenas Empresas, 2008). É uma entidade autônoma, de interesse público, que estimula o empreendedorismo das mais variadas formas: com um plano nacional de educação, com o suporte às políticas públicas voltadas ao empreendedorismo e com um sem-número de prêmios, feiras, jogos, publicações, cursos e eventos.

Esse serviço nasceu como Centro Brasileiro de Apoio às Pequenas e Médias Empresas, o Cebrae, em 1972. Foi a primeira entidade governamental de apoio ao pequeno negócio em nosso país, e teve seu fortalecimento no governo de Ernesto Geisel, fazendo parte do Plano de Desenvolvimento Nacional, que incluía o apoio às médias e pequenas empresas. Na transição para o regime democrático, os objetivos do centro foram modificados várias vezes, resultando em quinze estatutos diferentes ao longo de dez anos (Melo, 2008). Na década de 1980, a extinção do Cebrae foi várias vezes discutida, mas o centro sobreviveu à "década perdida". E mais: teve sua função garantida na Constituição de 1988, com a inclusão do Art. $179^{4}$ (Lopes, 2001; Melo, 2008; Uchôa de Oliveira, 2020).

Contudo, com a reforma administrativa de 1990, promovida por Collor de Mello, o Cebrae foi extinto. Por sua atuação tanto midiática (revista e programa de TV) quanto política (inclusão das pequenas empresas na nova Carta Constitucional), o Cebrae foi transformado em Sebrae, e passou a ser parte do Sistema ${ }^{5}$. Garantida sua sobrevivência por meio de orçamento e força de lei, o Sebrae expandiu sua atuação nacionalmente na década de 1990, ao longo dos dois governos de Fernando Henrique Cardoso. Portanto, esse serviço teve sua expansão na "década neoliberal", ou seja, das "reformas neoliberais" empreendidas pelos governos do Estado brasileiro (Massimo, 2013).

4 O artigo dispõe sobre tratamento jurídico diferenciado às microempresas e às empresas de pequeno porte, para o incentivo na simplificação de suas obrigações administrativas, tributárias, previdenciárias e creditícias, ou na eliminação ou redução destas por meio de Lei.

5 Segundo Oliveira (2014), o Sistema S surgiu nos anos de 1940 sob a ditadura do Estado Novo, no mesmo período da Consolidação das Leis Trabalhistas (CLT). Um conjunto de contribuições parafiscais foi instituído por diferentes leis por Getúlio Vargas, sendo esses recursos a base para a fundação do sistema. Essas contribuições advêm da folha de salários das empresas pertencentes à categoria profissional correspondente, seja da indústria, do comércio seja dos transportes, por exemplo. A Secretaria da Receita Federal do Brasil (SRFB) arrecada os valores e os repassa às entidades nomeadas de Serviços Sociais Autônomos, que não integram a administração pública, mas prestam serviços de interesse público. Nesse sentido, podem ser chamados de serviços "paraestatais". 
Melo aponta que, antes da entrada do novo milênio, o Sebrae formulou uma autocrítica registrada no documento Reinvenção do Sebrae (Sebrae, 1999, citado por Melo, 2008, p. 68), em que foi defendida uma "atualização da entidade diante de uma nova realidade social", em que "milhares" de pequenos empresários e empreendedores passariam a ser "milhões", incluindo os empreendedores informais e "ampliando-se a cultura de "união faz a força" (Melo, 2008, p. 68). É também a partir dos anos 2000 que o Sebrae começou a definir-se mais como um gestor de programas que como um realizador desses programas. Passou, por isso, a investir e publicar diversas pesquisas sobre o mercado de trabalho brasileiro, especialmente pesquisas sobre empreendedorismo.

Dentre as várias pesquisas que o Sebrae financia e participa, destaca-se a pesquisa realizada anualmente desde 2000 e que tem como resultado o relatório Empreendedorismo no Brasil (Fernandes, 2019). Essa pesquisa é realizada pelo consórcio Global Entrepreneurship Monitor (GEM), uma ferramenta para monitorar o empreendedorismo no mundo, inaugurada em 1997 por estudiosos da London School of Business, do Reino Unido, e da Babson College, dos Estados Unidos da América. No Brasil, essa pesquisa tem o suporte de instituições de ensino superior, como a Fundação Getúlio Vargas. Os relatórios dessa pesquisa são baseados em entrevistas e questionários respondidos por especialistas brasileiros em empreendedorismo e em questionários aplicados à população adulta dos países participantes.

A justificativa para monitorar o empreendedorismo no mundo é a "forte correlação" entre desenvolvimento econômico e atividade empreendedora, sendo os Estados Unidos da América a mais perfeita tradução disso. Dessa maneira, seria preciso entender tal correlação e utilizá-la como a referência para os demais países, estabelecendo critérios para fortalecê-la. No depoimento de um especialista que consta do relatório Empreendedorismo no Brasil de 2003, tem-se um exemplo da referência que deve ser seguida. Assim diz o especialista: "nos EUA, qualquer pequeno negociante é visto como alguém que pode vir a ser um Bill Gates" (Global Entrepreneurship Monitor, 2004, p. 62).

A metodologia desse monitoramento promove uma definição específica de empreendedorismo: qualquer iniciativa para criar um novo negócio ou empreendimento, incluindo "uma atividade autônoma, uma nova empresa ou a expansão de um empreendimento existente" - o que pode ser feito por um único indivíduo ou um grupo de indivíduos (Global Entrepreneurship Monitor, 2017, p. 109, grifos nossos). Além disso, o monitoramento promove uma separação entre países mais e menos voltados à inovação. Há, portanto, etapas em relação ao desenvolvimento econômico.

O próprio GEM mediou a utilização das pesquisas no Brasil, em um relatório sobre sua influência nas políticas públicas para o empreendedorismo no mundo (Global Entrepreneurship Monitor, 2018, pp. 7-8). Tendo o Sebrae como seu principal stakeholder brasileiro, os resultados dessa pesquisa são disseminados nas unidades estaduais do serviço e disponibilizados para todos os gestores da instituição. Também são disseminados na esfera federal do governo brasileiro, o que abarcava, por exemplo, o Ministério da Fazenda e a Secretaria da Micro e Pequena Empresa. As informações do GEM serviram ao Sebrae para a criação da figura do Microempreendedor Individual (MEI). Essa figura trouxe a formalização de mais de 9 milhões de trabalhadores autônomos que ganham até $\mathrm{R} \$$ 81.000,00 por ano. Atualmente, diaristas, entregadores e motoristas de aplicativos podem ser MEI.

Mas aonde queremos chegar com a descrição de uma "rede intrincada" entre revista, programa de TV, instituição, pesquisa, especialistas e lei? Vejamos.

\section{Instrumentos para pensarmos o empreendedorismo}

O que essa rede intrincada nos fornece é a sustentação para formularmos um diagnóstico sobre o tema e apresentarmos os instrumentos de pensamento dos quais nos apropriamos. Dividiremos esse diagnóstico em três partes. A primeira pode ser resumida na seguinte afirmação: o empreendedorismo é uma demanda.

\section{8}




\section{O empreendedorismo é uma demanda}

Ao procurar pelos significados da palavra demanda, encontramos o sentido de buscar e de solicitar ou exigir algo. Ainda, demanda pode ter o sentido de polêmica, carência evidente ou questionamento (Michaelis Dicionário Brasileiro da Língua Portuguesa, 2020). São as primeiras acepções do termo aquelas com as quais pensamos o empreendedorismo. $\mathrm{O}$ empreendedorismo é uma demanda porque é uma exigência e, como tal, se impõe como indiscutível: "somos todos empreendedores". Mais que uma possibilidade de inserção econômica, temos uma demanda de que sejamos todos empreendedores.

A expressão demanda empreendedora é um empréstimo e uma adaptação que fazemos das ideias de Ulrich Bröckling (2015). Empréstimo, pois o autor se utiliza dela, e adaptação, pois ele não a define em detalhes. A preocupação desse autor é dar nome ao constante chamado para a ação empreendedora. À novidade mais aterradora sintetizada por Gilles Deleuze ${ }^{6}$, Bröckling (2015, p. 11, tradução nossa) adiciona outra não menos terrificante: "a injunção de que todos devem transformar a si mesmos, até o último rincão de suas almas, em empreendedores em missão própria”. Para ele, essa injunção forma um esquema interpretativo complexo, um self empreendedor, que deve ser utilizado por todos para compreenderem a si mesmos e a suas vidas. A preocupação de Bröckling, da qual compartilhamos, está na composição de uma "genealogia da subjetivação" ou, de outra forma, de uma "analítica das governamentalidades" (Moisander, Groß \& Eräranta, 2018).

Para Bröckling (2015), não há algo como uma entidade ou um sujeito empreendedor completamente formado pela demanda de empreender. Ele indica que o self empreendedor está em constante formação; é o potencial, o aprendizado e a formação para ser empreendedor. Por isso, o autor indica que

O self empreendedor não possui nome nem endereço. Espécies não podem ser encontradas nem em escritórios, nem em startups. Tampouco é o que as pesquisas empíricas das ciências sociais indicam como sendo uma "personalidade modal", a construção estatística de um sujeito mediano que combine os traços mais comuns de personalidade em um determinado grupo. Não é o mais novo tipo social, depurado em entrevistas ou estudos de caso psicanalíticos. Não é uma máscara de caráter como na crítica marxiana da ideologia, nem é um roteiro da sociologia do interacionismo. O termo "self empreendedor" não denota uma entidade empírica observável, mas uma maneira de abordar os indivíduos como povo, de alterá-los e fazer com que eles se alterem de uma forma particular. . . . O self empreendedor é um sujeito no gerúndio - não é algo que existe, mas algo que deve ser trazido à existência (Bröckling, 2015, p. 20, tradução nossa).

Para ser trazido à existência, esse sujeito deve ser constantemente demandado. A nosso ver, a expressão demanda empreendedora, mais que o substantivo empreendedorismo, enfatiza o intenso e contínuo imperativo para uma forma de inserção econômica que também se espraia como um modelo de organização social e comportamental no neoliberalismo (Marttila, 2018).

Assim como Bröckling, Tomas Marttila (2013a, 2013b, 2018) enfatiza a necessidade de compreendermos a "empreendedorização da sociedade", ou seja, de compreendermos um processo histórico que viabiliza a disseminação de conceitos, ideias, e racionalidades neoliberais. Bem como Bröckling, Marttila desenvolve o significado dessa expressão baseando-se nos trabalhos de Nikolas Rose (1990; 1999) e Paul DuGay (1996), nos quais identifica a conviç̧ão própria do neoliberalismo de que indivíduos, instituições e organizações não podem funcionar plenamente se não adotarem qualidades e competências empreendedoras. Nessa proposta, o autor elucida que é preciso subverter

6 "Informam-nos que as empresas têm uma alma, o que é efetivamente a notícia mais terrificante do mundo" (Deleuze, 1992, p. 222).

7 Tradução livre do termo em inglês "entrepreneurialization of society". 
o argumento mais comum de que o empreendedor tem servido como um modelo de ação para grande parte dos atores sociais e voltar a atenção às mudanças históricas que levaram à empreendedorização da sociedade, ou, ainda, que levaram à governamentalização do empreendedor.

\section{A demanda empreendedora é um dispositivo de governo neoliberal}

Utilizando-nos das ideias de Bröckling e de Marttila, indicamos que a demanda empreendedora pode ser compreendida como um "dispositivo" de governo neoliberal. Isso constitui a segunda parte de nosso argumento. Retomemos as duas partes em perspectiva: o empreendedorismo é uma demanda, e tal demanda pode ser compreendida como um dispositivo de governo neoliberal. Tal afirmação remete-nos aos conceitos foucaultianos de "dispositivo" e de "governo", além de apresentar um entendimento específico sobre o que é "neoliberalismo". Aprofundamos esses conceitos em outra publicação (Uchôa de Oliveira, 2020), que aqui tentamos simplificar.

O dispositivo é uma rede dinâmica e móvel em que "discursos, instituições, organizações arquitetônicas, decisões regulamentares, leis, medidas administrativas, enunciados científicos, proposições filosóficas, morais, filantrópicas" (Foucault, 2014, p. 364) são colocadas em articulações uns com os outros para determinados fins. Sobretudo, para direcionar os processos de vida (Lemke, 2018, p. 48), em determinado momento histórico, com efeitos que se reinvestem, em uma tentativa de englobar as resistências ao próprio dispositivo, refazendo-o também pelos problemas que dele surgem. Em um sentido mais amplo, o dispositivo tem por objetivo o governo.

Se seguirmos as indicações de Michel Foucault, governo não pode ser identificado com Estado, como no uso mais comum da palavra nos nossos dias: "o governo de determinado partido", "as medidas tomadas pelo governo" etc. Governo, no sentido empregado por esse autor, tem a ver com uma forma de exercício do poder. O poder é da ordem do governo. Pode-se afirmar que o poder se exerce ao "conduzir condutas" e "ordenar probabilidades" (Foucault, 2010b, p. 244). A palavra conduta é a tradução encontrada pelo pensador francês em que se articulam tanto o sentido da condução dos outros quanto o sentido da condução de si.

Essa palavra é a chave para a compreensão da dinâmica e da coincidência entre governar a si mesmo, governar os outros e governar as coisas. A melhor condução envolve o conhecimento de todos os aspectos governados: é uma tentativa de forjar a conduta racionalmente. A racionalidade, no entanto, não deve ser compreendida como a Razão, mas como diferentes maneiras de pensar e calcular, de definir propósitos e de gerir conhecimento (Dean, 2010, p. 19). Foucault se interessa pelo estudo dessas racionalidades, principalmente em seus cursos Segurança, território, população (Foucault, 2008a) e Nascimento da biopolítica (Foucault. 2008b). Para o estudo dessas racionalidades de governo, ele propõe a noção de "governamentalidade".

A governamentalidade é o instrumento foucaultiano para a compreensão das várias racionalidades de governo que são estatizadas, ou seja, que não derivam do Estado, mas são incorporadas por ele. Surge como uma bússola utilizada por Foucault para localizar-se em uma "genealogia do Estado Moderno" (Avelino, 2016; Bröckling, Krassman \& Lemke, 2010). Nessa genealogia, Foucault marcará três formas particulares de governo: a Razão de Estado, a polícia (ou o Estado administrativo) e o liberalismo. Essas racionalidades específicas de governo não contam uma história evolutiva de modernização do Estado, ao contrário, contam de rupturas e de variadas tecnologias de poder que nele são incorporadas.

Sobre a Razão de Estado, Foucault explica que é o esforço para diferenciar os princípios e métodos do Estado daqueles com os quais "Deus governa o mundo, um pai governa uma família, um líder governa uma comunidade” (Foucault, 2013, p. 74, tradução nossa). Sobre a polícia, ele elucida que não se trata da instituição que atualmente chamamos de polícia, mas da definição da natureza dos objetos da atividade racional do Estado, da definição dos objetivos que o Estado deve 
alcançar e dos instrumentos gerais que ele emprega para isso (Foucault, 2013, p. 74). A Razão de Estado diz respeito ao fortalecimento do próprio Estado, em sua natureza, em sua extensão e em concorrência com outros Estados; enquanto a polícia diz respeito ao que concerne à vida, isto é, a toda e qualquer atividade realizada pelo ser humano, para que dela se derive alguma produtividade.

À terceira forma de governo, o liberalismo, Foucault dedicou uma considerável investigação. Para ele, a racionalidade liberal rompe com a Razão de Estado que, "desde o fim do século XVI, havia procurado na existência e no fortalecimento do Estado o fim capaz de justificar uma governamentalidade crescente e de regular seu desenvolvimento". Ao mesmo tempo, rompe com o princípio da polícia em que "não se presta atenção suficiente, coisas demais escapam, áreas demasiado numerosas carecem de regulação e de regulamento, faltam ordem e administração - em suma, governa-se pouco demais". Na racionalidade liberal o governo não tem sua razão de ser em si mesmo, nem em seus instrumentos estatais, nem em sua maximização. $O$ princípio da racionalidade liberal é o de que "sempre se governa demais" (Foucault, 2008b, pp. 432-434).

Para legitimação do governo liberal, temos de adicionar ao menos duas outras noções, localizadas no jogo entre o poder político e o poder pastoral (Veiga Neto, 2000; Bröckling et al.). O poder político vem da noção antiga de pólis, organizada ao redor da lei, da universalidade e do público. O poder pastoral, por sua vez, representa a concepção cristã da relação entre o pastor e seu rebanho, de líderes e liderados, em que se guia cada indivíduo para a salvação. O pastorado cristão tem por objetivo o cuidado com a "verdade" de todo e cada indivíduo, sendo essa "verdade" guardada pela autoridade pastoral. Chamemos o pastorado de poder individualizante (Foucault, 2013, p. 62). Entre a pólis e o pastorado está a "inteligência" do Estado Moderno (Donzelot, 2005, citado por Avelino, 2016, pp. 262-263).

Veiga-Neto indica que, para a dinâmica da pólis, foram necessários novos saberes que pensavam uma universalidade dos indivíduos, isto é, que pensavam na população: "inicialmente, a Estatística, a Economia e a Demografia; depois, a Saúde Pública; logo adiante, toda a 'área psi' (a Psiquiatria, a Psicologia, a Psicanálise)" (Veiga Neto, 2000, pp. 205-206). Aqui é preciso que enfatizemos a importância da noção foucaultiana de "biopoder". Este é um termo que lança um novo elemento ao problema de governo na obra de Michel Foucault. Trata-se da tecnologia que se exerce sobre a população.

Isto é, emerge a preocupação de cuidar das regularidades e acidentes de uma massa global, a população, e tudo que dela pode ser nomeado, medido e acompanhado para melhor governar e garantir mais a produtividade da totalidade dos corpos do que a sua destruição. Regula-se então a natalidade, a mortalidade, o desemprego etc. Dessa forma, o bom governo faz-se pela emergência dessa nova leva de conhecimento, surgida com o novo problema político da população. Por sua vez, ao jogo do poder pastoral serviu a disciplina, com as técnicas de confissão, de vigilância de si mesmo, "capaz[es] de colocar para dentro de cada indivíduo o olhar do soberano que se apaga com o raiar da Modernidade" (Veiga-Neto, 2000, p. 206). A hipótese de Foucault é que as técnicas do pastorado eventualmente produziram formas de subjetificação com as quais o Estado Moderno e a sociedade capitalista desenvolveram-se, sobretudo a partir do século XVIII.

Ademais, na racionalidade liberal, o mercado transformou-se em um lugar de veridicidade sobre o governo. A teoria econômica, com a relação preço-valor, possibilita que o mercado seja revelador de uma verdade. O mecanismo natural do mercado e a formação livre dos preços (justos, bons, em suma, "verdadeiros") tornam-se uma medida do bom governo. "O mercado é que vai fazer que o governo, agora, para poder ser um bom governo, funcione com base na verdade" (Foucault, 2008b, pp. 44-45).

A lógica possibilitada pelo mercado é atrelada à "segunda grande descoberta do século XVIII: ... Se o mundo físico é governado pelo movimento [primeira grande descoberta do século XVIII], diziam os economistas, é o interesse que governa o mundo moral" (Avelino, 2016, p. 264). Se o interesse rege a conduta moral, ir contra o próprio interesse seria ilógico. 
O interesse, dessa forma, torna-se um princípio de governo; ao mesmo tempo, torna-se objeto de manipulação. Essa é uma imbricação importante, em que o interesse "verdadeiro" será aquele que se conecta à lógica "natural" do mercado. O indivíduo liberal é formulado como um "sujeito que calcula sua ação para obter o maior ganho possível" (Avelino, 2016, p. 264): é um sujeito econômico.

Até o início do século XX, a problemática do liberalismo estava posta na demarcação da ação do governo: delimitar o seu espaço de intervenção para criar um espaço livre, o mercado. No entanto, o deixar agir do naturalismo mercadológico sofre um grave revés em meados do século XX, instaurando uma crise da governamentalidade liberal. Ambrózio (2012, pp. 55-56) aponta a crise de 1929 como a evidência patente de que "[a] mão invisível não era passível de comprovação em virtude das ações individuais dos capitalistas terem guiado a economia mundial a uma crise nunca antes vista".

A essa crise será dada uma resposta ou uma reconfiguração das ideias liberais: a problemática de até que ponto se deve governar será suplantada pela pergunta: como se deve governar? Coloca-se um problema de método em detrimento dos problemas do que se deve ou não governar. Tudo será (ou poderá ser) governável - governamentalizável -, o problema está posto em como fazê-lo. A resposta à crise de governamentalidade liberal é o neoliberalismo.

Davies (2014, p. 311) aponta que, em uma revisão bibliográfica da literatura sobre o neoliberalismo, podemos encontrar ao menos quatro pontos compartilhados por muitos autores de diferentes abordagens. O primeiro ponto: o liberalismo é para os neoliberais uma fonte de inspiração, mas não um modelo a ser seguido; portanto, o neoliberalismo é uma inovação e não um programa "nostálgico" do laissez-faire liberal. Em segundo, as políticas neoliberais estão para além dos limites do mercado, mirando instituições outras, por exemplo, as universidades, os serviços públicos em geral e os sindicatos.

Esse foco em instituições "fora" do mercado tem por objetivo colocá-las para "dentro" do mercado, reinventando-as nos moldes do mercado, ou, ainda, enfraquecendo-as ou neutralizandoas. O terceiro ponto seria o de que, para criar e atingir seus objetivos, o neoliberalismo precisa de instrumentos estatais robustos, não podendo depender apenas das forças do mercado. Os estados neoliberais devem produzir e reproduzir as regras institucionais e de conduta para os indivíduos, formando uma certa visão política e ética. O quarto e último ponto diz respeito à visão dominada pela ideia de competição, ou seja, "da produção de desigualdade". Competição e desigualdade são valores positivos no neoliberalismo. A essa revisão de Davies, podemos acrescentar que, ao neoliberalismo é inerente uma agenda de políticas públicas que engloba o "chavão" da "santíssima trindade" da liberalização econômica, privatização e desregulação (Higgott, 2000; Plehwe \& Walpen, 2007), o que não significa "Estado mínimo".

É importante que estes pontos mais ou menos compartilhados de nenhuma forma sejam confundidos com a noção do neoliberalismo como uma forma monolítica e coerente de governar. De acordo com Dean, é preciso que pensemos "as racionalidades neoliberais em complexas inter-relações com o neoconservadorismo e as reações populistas e antigovernamentais, bem como nos debates sobre moralidade e comunidade" (Dean, 2010, pp. 149-150, tradução nossa). Podemos considerar o neoliberalismo como a racionalidade contemporânea em maior uso para o governo, mas que funciona somente dentro de um campo de contestações no qual existam múltiplas racionalidades de governo.

\section{O elemento colonial/moderno da demanda empreendedora}

Além desses pontos de convergência sobre o neoliberalismo, é preciso observar o "euroamericanocentrismo" impregnado em tal noção. Nas palavras de Raewyn Connell e Nour Dados (2014; Dados \& Connell, 2018), ao falarmos de neoliberalismo, está implícita a hegemonia de uma perspectiva geopolítica referenciada ao Norte. Assim, é necessário explicitar essa perspectiva 
e colocar os dispositivos de governo neoliberal como parte de uma continuidade, ou seja, como parte da narrativa da colonialidade/modernidade.

Retomemos nosso diagnóstico em perspectiva pela terceira vez: o empreendedorismo é uma demanda e tal demanda deve ser compreendida como um dispositivo de governo neoliberal, sendo, por isso, parte também de uma continuidade colonial e moderna. O que quer dizer que a demanda empreendedora funciona em uma rede heterogênea e heterárquica, sustentada também na colonialidade/modernidade.

A colonialidade é uma expressão que amplia o termo colonialismo, pois estabelece uma diferença significativa entre a expropriação e exploração territorial e econômica da Europa em suas colônias, e uma "expropriação epistêmica" que subjuga os conhecimentos produzidos nessas colônias, fazendo deles um "passado" (ou o não evoluído) da ciência moderna (Castro-Gómez, 2007, p. 27). A modernidade, por sua vez, é um modelo interpretativo hegemônico que se desenvolve a partir do século XVIII, com suas raízes na Europa, por meio de eventos históricos europeus, como a Reforma Protestante, o Renascimento, o Iluminismo e a Revolução Francesa. A partir dessas experiências intraeuropeias, difundiu-se para o mundo a "modernidade" (Castro-Gómez, 2005, p. 45).

Eurocêntrica, a modernidade seria "a pretensão que identifica a particularidade europeia com a universalidade" (Castro-Gómez, 2005, p. 46). Citando Enrique Dussel (1992), Castro-Gómez (2005, p. 46) indica que essa "modernidade" implica em uma "falácia desenvolvimentista", o que quer dizer que a modernidade é o objetivo das sociedades que, em "etapas de desenvolvimento", atingiriam seu futuro e completariam sua história. O que é, em todo caso, completar o sentido da história europeia e americana em seu destino e razão de existência. $\mathrm{Na}$ ideia de modernidade juntam-se o evolucionismo e o dualismo, o qual seja, a ideia de um ponto final para o processo de evolução e a separação entre categorias binárias, sendo a principal a de europeu e não europeu. De acordo com Dussel (1992, citado por Castro-Gómez, 2005, p. 46), "a civilização europeia é o 'télos' da história mundial".

Partir de uma leitura decolonial utilizando a noção de colonialidade/modernidade altera pressupostos como

o de que a divisão internacional do trabalho entre centro e periferia, assim como a hierarquização étnico-racial das populações, formada por vários séculos de expansão colonial europeia, não se transformou significativamente com o fim do colonialismo e a formação dos Estados-nação na periferia. Assistimos, sim, a uma transição do colonialismo moderno à colonialidade global, processo que certamente tem transformado as formas de dominação introduzidas pela modernidade, mas não a estrutura de relações centro-periferia em escala mundial (Castro-Gómez, 2005, p. 46).

Especificamente, na "modernidade" a ideia de raça torna-se uma marca de classificação social na qual diferenças fenotípicas entre conquistadores e conquistados produziram "identidades sociais" como índios, negros e mestiços e, igualmente, a de europeu. Essas "identidades" foram forjadas em uma relação de dominação, tornando-as "associadas às hierarquias, lugares e papéis sociais correspondentes, como constitutivas delas, e, consequentemente, ao padrão de dominação que se impunha" (Quijano, 2005, p. 117).

Essa classificação social moderna encontra-se, em certa medida, com as ideias de Michel Foucault, embora estas sejam intraeuropeias. Foucault (2010a, pp. 214-217) assinala algo semelhante ao que Aníbal Quijano (2005) explica: a raça seria elemento fundamental para o funcionamento do Estado. Para Foucault, "o racismo vai se desenvolver primo com a colonização, ou seja, com o genocídio colonizador” (2010a, p. 216). Trata-se do elemento que funciona como fragmentador das funções de vida, do biológico. O racismo é o corte entre a vida e a morte que emerge pela racionalidade biopolítica. 
O racismo então pode ser compreendido como "uma técnica de poder, uma tecnologia de poder" fundamental no Estado moderno (Foucault, 2010a, p. 217). Para Foucault, o racismo teria duas articulações: uma intraeuropeia, "com base nos movimentos das nacionalidades na Europa e nas lutas das nacionalidades contra os grandes aparelhos de Estado (essencialmente austríaco e russo)"; e outra extraeuropeia, "a partir da política de colonização europeia" no restante do mundo (2010a, p. 51). Nessa técnica de poder, não haveria uma exterioridade entre as raças, mas uma evolução da mesma raça em uma "super-raça". Ou seja, o racismo como técnica de poder na modernidade é "o reaparecimento, a partir de uma raça, de seu próprio passado" (2010a, p. 51). Há uma "sub-raça", que é o anterior no caminho da evolução para a "super-raça".

Dessa forma, a raça ganha protagonismo nas análises da modernidade. Isso quer dizer que, para pensar a globalidade do sistema de poder hegemônico atual, é necessário pensar para além do determinismo econômico, ou melhor, deve-se pensar para além de hierarquias entre determinantes sociais, políticos e econômicos. Há de se lembrar que esse exercício de poder deve ser analisado como heterárquico. $\mathrm{O}$ que quer dizer, primeiramente, que o poder está posto em rede e funciona em cadeia. Nesse funcionamento, regimes mais complexos de poder emergem de regimes menos complexos, sendo os primeiros "dispositivos de captura" em que se apropriam de relações de poder constituídas de antemão, incorporando os segundos à sua lógica. "Não é a dominação global que se pluraliza e repercute até embaixo" (Foucault, 2010a, p. 27); a heterarquia do poder é precisamente o contrário. Dessa forma, não há uma lógica de poder que se espraia, mas diferentes lógicas acopladas em diferentes conjunturas históricas, que se podem "entramar" sem que necessariamente haja uma hierarquia entre essas lógicas.

Diante do elemento de colonialidade do poder, de suas técnicas e de sua heterarquia, localizamos nossas análises nas fronteiras entre o pensamento decolonial e o pensamento de Foucault. Tal localização quer dizer que reconhecemos afinidades: a raça como elemento fundador do exercício do poder na modernidade é uma delas, bem como a compreensão do parâmetro da raça para o exercício do poder como uma formulação que une evolucionismo, dualismo e universalismo. Outra afinidade está na globalidade do exercício de poder que, mesmo que em analíticas distintas entre hierarquia - como no sistema-mundo de que fala Wallerstein (2004) - e heterarquia (CastroGómez, 2007), indicam um exercício de poder de "dominação global”, distinto do "universal".

\section{Nossa proposta}

O que buscamos até aqui foi estabelecer uma compreensão do empreendedorismo como uma demanda que funcione como um dispositivo de governo neoliberal, o qual seja, em uma rede intrincada de discursos, práticas e instituições que funcione por meio da racionalidade neoliberal. O que nos remete a uma compreensão sobre o neoliberalismo que dá as bases para que pensemos seus dispositivos de governo em suas descontinuidades, mas também em suas permanências - principalmente na continuidade do elemento colonial/moderno em que a vida em sociedade é regulada.

Neste sentido, propomos que o empreendedorismo seja deslocado do sujeito, isto é, de uma "consciência", "motivação", "comportamento", "espírito" empreendedor para que seja estudado como uma constante chamada à ação, um processo de aprendizado imposto como inescapável. O empreendedorismo configura-se como uma demanda que não está localizada no sujeito, mas que o mobiliza.

Essa demanda circula e funciona por meio de uma rede heterogênea de discursos e práticas, não possui um posto central ou único de disseminação e é produzida e reproduzida em muitos espaços, em diferentes contextos. Coachs, gurus de negócios, revistas, programas de TV e rádio, canais de streaming, podcasts, blogs e perfis em redes sociais, manuais, artigos acadêmicos das mais variadas 
disciplinas, pesquisas, instituições e organizações privadas e públicas, think tanks, universidades e escolas, discursos de políticos e economistas, pareceres no Legislativo e no Judiciário são apenas alguns dos incontáveis veículos transmissores dessa demanda.

Todas as outras formas de trabalhar, de conduzir-se, de relacionar-se com os outros são expropriadas para que em seu lugar sejam localizados a narrativa empreendedora, o vocabulário empreendedor, o comportamento empreendedor e o espírito empreendedor. Mesmo no emprego, é possível falar do intraempreendedorismo. Até que "se pense" inescapavelmente como um "empreendedor" e que tudo possa ser adjetivado a partir do empreendedorismo.

A demanda empreendedora conserva um destino a partir de um determinado passado por meio de qualquer ação, comportamento ou discurso. Isto é, localiza-se o empreendedorismo no passado: por exemplo, nos donatários, nos bandeirantes, nos mestres do açúcar que são "exemplos" dos homens empreendedores que "fizeram o Brasil" (Mourão, 2019); e em qualquer ato, ação ou comportamento, até mesmo no trabalho voluntário e de fé da recém-canonizada Santa Dulce dos Pobres (Amaral, 2019). Mas, também se conserva uma orientação para o futuro, um destino empreendedor pelo aprendizado contínuo, por exemplo, nas escolas em que crianças a partir de três meses de idade devem ser expostas a atividades que desenvolvam "habilidades" como o empreendedorismo (Matias, 2019).

Este é propriamente o elemento de colonialidade da demanda empreendedora: a incessante imposição dos termos empreendedores em uso, em circulação e reprodução. Ademais, o elemento de colonialidade/modernidade é o apelo da "modernização" para o "modernizar-se". No entanto, é preciso perguntar, que "empreendedor" e que "modernização" impõem essa demanda? Embora não esteja localizada no sujeito, a demanda empreendedora efetiva-se por meio de uma determinada "representação de sujeito". E, neste ponto, diferenciamos nossa análise das de Bröckling (2015), pois compreendemos que, apesar de não ser uma entidade formatada em definitivo, mas em um processo contínuo de formação, o self empreendedor e o que com ele se demanda dos sujeitos possuem um parâmetro.

A demanda empreendedora entroniza a experiência euroamericana como aquela que se desdobrou para a "melhor versão" de uma sociedade. É sexista, racista e classista por excelência. O "empreendedor" (ou como ele é representado em "espírito", “comportamento" e "narrativa") é "Bill Gates": o homem euroamericano, branco, adulto, das classes médias e altas, com mais anos de escolaridade que a média da população e com oportunidades diversas de educação e formação ${ }^{8}$. Esse "empreendedor" é o parâmetro, e, por isso mesmo, quem corresponde a ele tem maior probabilidade de cumprir satisfatoriamente a demanda, tornando-se "seu próprio patrão" e a "melhor versão de si mesmo". Apesar de não ser uma "entidade empírica observável" em definitivo, é a norma, um "espaço de veridicidade" sobre o trabalho e uma maneira de manejar "indivíduos como povo" pelo "desejo de se manter e do medo de estar fora de uma ordem social sustentada por mecanismos de mercado" (Bröckling, 2015, p. 20).

Assim, também se tem a "modernização" como parte elementar da demanda por empreender, impondo o parâmetro do Norte global, das "economias desenvolvidas", dos "países desenvolvidos", dos "países voltados à inovação", enfim, do "primeiro mundo". A demanda empreendedora é parte de um "paradigma da modernização", uma forma de continuidade de ideias como as de Walt Rostow (1971), de acordo com as quais as sociedades passavam por etapas de desenvolvimento para atingir a inevitável "modernização", ou seja, a "euroamericanização" como destino e como método.

Por fim, propomos que a demanda empreendedora seja compreendida como um dispositivo de governo neoliberal formulado na urgência histórica da crise do emprego ao final do século XX e,

8 Nos dados do relatório GEM de 2016, identificamos que os empreendedores estabelecidos (isto é, suas empresas já possuem mais de três anos) são também predominantemente "homens (57,3\%), com idade entre 35 e 44 anos (30,1\%), possuem renda familiar entre três e seis salários mínimos (34,6\%), possuem segundo grau completo ou estão cursando o ensino superior (38,1\%), são casados (45,7\%) e são majoritariamente pardos e brancos (86\%)" (GEM, 2017, p. 51). 
nesse sentido, como uma resposta a uma crise de governo. Sendo o emprego não mais "possível", e sendo o mercado o único regime de veridicidade "possível", a demanda empreendedora abocanha as várias outras formas de trabalhar que lhes são anteriores e exteriores - em outras palavras, tenta abarcar a polimorfia do trabalho -, agora sob a valorização do risco e do precário na condução de si e dos outros, conforme a racionalidade neoliberal.

A demanda empreendedora é o que governamentaliza, no contexto do Sul, a criação de trabalho e a gestão da sobrevivência; o bico, a viração e a correria são agora as formas incentivadas e predominantes de trabalho. Cabe o aviso de que não são formas de trabalho minoritárias até a reestruturação produtiva dos anos 1970 - do contrário, sempre foram as formas majoritárias. O que queremos dizer é que o que antes era majoritário, mas visto como "problemático", passa a ser uma forma de governo.

São as formas estatizadas de trabalho, em que o emprego não é mais nem o objetivo nem a referência. Por isso, é possível afirmar que a demanda empreendedora organiza e governa as várias formas precárias de trabalho em que os trabalhadores já se encontravam. A diarista, os entregadores e os motoristas de aplicativo são exemplos disso. Talvez, um dos exemplos mais agudos dessa governamentalização da precariedade esteja posto na reforma trabalhista de 2017, em que se autoriza a jornada intermitente, a dificuldade de acesso dos trabalhadores à Justiça, o trabalho autônomo, a terceirização e a soberania do negociado sobre o legislado (Maior \& Severo, 2017).

\section{Referências}

Amaral, T. (2019, 13 de outubro). A Irmã Dulce começou... Recuperado de https://www.facebook.com/tabataamaralSP/ photos/pb.201596403728972.-2207520000.1571085721./509754949579781/?type =3\&theater

Ambrózio, A. (2012). Governamentalidade neoliberal: disciplina, biopolítica e empresariamento da vida. Kínesis, 4(8), 40-60.

Avelino, N. (2016). Foucault e a racionalidade (neo)liberal. Revista Brasileira de Ciência Política, 21, 227-284.

Bastos, J. A. (2019). Servidores, funcionários, terceirizados e empregados: a babel dos vínculos, cotidiano de trabalho e vivências dos trabalhadores em um serviço público. Tese de Doutorado, Universidade de São Paulo, São Paulo, SP.

Bröckling, U. (2015). The entrepreneurial self: fabricating a new type of subject. London: Sage.

Bröckling, U., Krasmann, S. \& Lemke, T. (Eds.). (2010). Governmentality: current issues and future challenges. Londres: Routledge.

Castro-Gómez, S. (2005). La poscolonialidad explicada a los niños. Bogotá: Universidad del Cauca y Universidad Javeriana. Castro-Gómez, S. (2007). Michel Foucault and the coloniality of power. Tabula rasa, (6), 153-172.

Connell, R. \& Dados, N. (2014). Where in the world does neoliberalism come from? Theory and Society, 43(2), 117-138.

Dados, N. \& Connell, R. (2018). Neoliberalism in world perspective: Southern origins and southern dynamics. In D. Cahill, M. Cooper, M. Konings \& D. Primrose (Eds.), The SAGE handbook of neoliberalism (pp. 28-39). London: Sage Publications.

Davies, W. (2014). Neoliberalism: a bibliographic review. Theory, Culture $\mathcal{E}$ Society, 31 (7/8), 309-317.

Dean, M. (2010). Governmentality: power and rule in modern society. London: Sage Publications.

Deleuze, G. (1992). Conversações. São Paulo: Editora 34.

DuGay, P. (1996). Consumption and identity at work. London: Sage Publications.

Fernandes, R. J. R. (2019). Análise crítica do discurso de apoio às MPMES e de fomento ao empreendedorismo no Brasil pós-redemocratização. Tese de Doutorado, Fundação Getúlio Vargas, São Paulo, SP.

Foucault, M. (2008a). Segurança, território, população: curso no Collège de France (1977-1978). São Paulo: Martins Fontes. Foucault, M. (2008b). Nascimento da biopolítica: curso no Collège de France (1978-1979). São Paulo: Martins Fontes.

Foucault, M. (2010a). Em defesa da sociedade: curso no Collège de France (1975-1976). São Paulo: Martins Fontes.

Foucault, M. (2010b). O sujeito e o poder (Apêndice da Primeira Edição 1982). In H. L. Dreyfus \& P. Rabinow, Michael Foucault: uma trajetória filosófica: para além do estruturalismo e da hermenêutica (pp. 273-295). Rio de Janeiro: Forense Universitária. 
Foucault, M. (2013). Politics, philosophy, culture: interviews and other writings, 1977-1984. Londres: Routledge.

Foucault, M. (2014). Microfísica do poder. Rio de Janeiro: Graal.

Global Entrepreneurship Monitor. (2004). Empreendedorismo no Brasil: 2003. Curitiba: Instituto Brasileiro de Qualificação Profissional.

Global Entrepreneurship Monitor. (2017). Empreendedorismo no Brasil: 2016. Curitiba, Instituto Brasileiro de Qualificação Profissional.

Global Entrepreneurship Monitor. (2018). The influence of GEM on Policy 2017/18. London: GEM Consortium.

Higgott, R. (2000). Contested globalization: the changing context and normative challenges. Review of International Studies, 26, 131-153.

Lemke, T. (2018). Rearticulando o conceito de dispositivo: combinando STS e Analítica do Governo. Mediações, 23(1), 32-62.

Lopes, E. B. (2001). O Sebrae e as relações público-privado no Brasil. Dissertação de mestrado, Universidade Estadual Paulista Júlio de Mesquita Filho, Araraquara, SP.

Maior, J. L. S. \& Severo, V. S. (2017). Manual da reforma trabalhista: pontos e contrapontos. São Paulo: AATSP.

Massimo, L. (2013). Como se explica o neoliberalismo no Brasil? Uma análise crítica dos artigos publicados na revista Dados. Revista de Sociologia e Política, 21 (47), 133-153. Recuperado de https://doi.org/10.1590/s0104-44782013000300010

Marttila, T. (2013a). Culture of enterprise in neoliberalism: specters of entrepreneurship. London: Routledge.

Marttila, T. (2013b). Whither governmentality research? A case study of the governmentalization of the entrepreneur in the French epistemological tradition. Forum: Qualitative Social Research, 14(3), 293-331.

Marttila, T. (2018). Neoliberalism, the knowledge-based economy and the entrepreneur as metaphor. In D. Cahill, M. Cooper, M. Konings \& D. Primrose (Eds.), The SAGE handbook of neoliberalism (pp. 565-579). London: Sage Publications.

Matias, L. (2019, 7 de setembro). Investimento na formação de líderes chega ao berçário. Folha de S.Paulo. Recuperado de https:/www1.folha.uol.com.br/educacao/2019/09/investimento-na-formacao-de-lideres-chega-ao-bercario.shtml

Melo, N. M. (2008). Sebrae e empreendedorismo: origem e desenvolvimento. Dissertação de mestrado, Universidade Federal de São Carlos, São Carlos, SP.

Michaelis Dicionário Brasileiro da Língua Portuguesa. (2020). Demanda. Recuperado de https://michaelis.uol.com.br/ moderno-portugues/busca/portugues-brasileiro/demanda/

Moisander, J., Groß, C. \& Eräranta, K. (2018). Mechanisms of biopower and neoliberal governmentality in precarious work: mobilizing the dependent self-employed as independent business owners. Human Relations, 71(3), 375-398.

Mourão, H. (2019, 27 de setembro). Donatários, bandeirantes, senhores... Recuperado de https://twitter.com/ generalmourao/status/1178436937683738624

Oliveira, A. (2014). Caixa-preta do sistema S: mais de $R \$ 15$ bilhões/ano em dinheiro público. Brasília, DF: Senado Federal.

Quijano, A. (2005). Colonialidade do poder, eurocentrismo e América Latina. In E. Lander (Org.), Por uma sociologia reflexiva: pesquisa qualitativa e cultura (pp.43-66). Petrópolis, RJ: Vozes.

Plehwe, D. \& Walpen, B. J. (2007). Between network and complex organization. In D. Plehwe, B. J. Walpen \& G. Neunhöffer (Eds.), Neoliberal hegemony: a global critique (pp. 45-68). London: Routledge.

Rose, N. (1990). Governing the soul: the shaping of the private self. London: Routledge.

Rose, N. (1999). Powers of freedom: reframing political thought. Cambridge: Cambridge University Press.

Rostow, W. W. (1971). Etapas do desenvolvimento econômico. Rio de Janeiro: Zahar.

Sato, L. (1993). A representação social do trabalho penoso. In M. J. P. Spink (Org.), O conhecimento no cotidiano: as representações sociais na perspectiva da psicologia social (pp. 188-211). São Paulo: Brasiliense.

Sato, L. (2002). Prevenção de agravos à saúde do trabalhador: replanejando o trabalho através das negociações cotidianas. Cadernos de Saúde Pública, São Paulo, 18(5), 1147-1157.

Sato, L. (2003). Psicologia, saúde e trabalho: distintas construções dos objetos "trabalho" e "organizações”. In Z. A. Trindade \& A. N. Andrade (Orgs.), Psicologia e saúde: um campo em construção (pp. 167-178). São Paulo: Casa do Psicólogo.

Sato, L. (2009). Juntando os pedaços. In M. H. S. Patto (Org.), A cidadania negada: políticas públicas e formas de viver (pp. 23-28). São Paulo: Caso do Psicólogo.

Sato, L. (2011). Psicologia e trabalho: focalizando as "profissões ignoradas". In B. Medrado \& W. Galindo (Orgs.), Psicologia social e seus movimentos: 30 anos de ABRAPSO (pp. 233-252). Recife: Ed. Universitária da UFPE. 
Sato, L. (2012). Feira livre: organização, trabalho e sociabilidade. São Paulo: Edusp.

Sato, L. (2017). Diferentes faces do trabalho no contexto urbano. In M. C. Coutinho, M. H. Bernardo \& L. Sato (Orgs.), Psicologia social do trabalho (pp. 151-174). Petrópolis, RJ: Vozes.

Sato, L., Coutinho, M. C. \& Bernardo, M. H. (2017). A perspectiva da psicologia social do trabalho. In M. C. Coutinho, M. H. Bernardo \& L. Sato (Orgs.), Psicologia social do trabalho (pp. 11-24). Petrópolis, RJ: Vozes.

Serviço Brasileiro de Apoio às Micro e Pequenas Empresas. (2008). Quem somos. Recuperado de https://www.sebrae. com.br/sites/PortalSebrae/canais_adicionais/conheca_quemsomos

Spink, P. K. (2012). Prefácio. In L. Sato, Feira livre: organização, trabalho e sociabilidade (pp. 13-20). São Paulo: Edusp, 2012. Uchôa de Oliveira, F. M. (2020). Somos todos empreendedores? A demanda empreendedora como dispositivo de governo neoliberal. Tese de doutorado, Universidade de São Paulo, São Paulo, SP.

Veiga-Neto, A. (2000). Educação e governamentalidade neoliberal: novos dispositivos, novas subjetividades. In V. Portocarreto \& G. Castelo Branco (Orgs.), Retratos de Foucault (pp. 179-217). Rio de Janeiro: Nau.

Wallerstein, E. (2004). Capitalismo histórico y movimientos antisistémicos: un análisis de sistemas-mundo. Barcelona: Akal.

\section{Endereço para correspondência}

flavia.muo@gmail.com
Recebido em: 11/11/2019

Revisado em: 08/06/2020

Aprovado em: 28/06/2020 